\title{
Analisis Kejadian Abrasi Kornea pada Pasien dengan Trikiasis Akibat Entropion
}

\author{
${ }^{1}$ I Dewa Ayu P. Savitri \\ ${ }^{2}$ Wenny P. Supit \\ ${ }^{3}$ Sigmund I. E. Tumewu
}

\author{
${ }^{1}$ Program Studi Pendidikan Dokter Fakultas Kedokteran Universitas Sam Ratulangi Manado \\ ${ }^{2}$ Bagian Ilmu Kesehatan Mata Fakultas Kedokteran Universitas Sam Ratulangi Manado \\ e-mail: asavitri99@yahoo.com
}

\begin{abstract}
Trichiasis is a condition of abnormal growth of eyelashes that results in scraping of the eyelashes on the corneal surface; therefore, ulceration or abrasion of the corneal can occur. One of the causes of trichiasis is entropion that can occur involutionally due to aging process. This study was aimed to obtain the correlation between incidence of corneal abrasion and trichiasis due to entropion. This was a prospective and analytical study. Subjects were elderly people at Panti Werdha Senja Cerah (nursing home) and elderly patients who visited the North Sulawesi Province Eye Hospital during September to November 2019. The result showed that there were 30 subjects with involutional entropion that reached the peak at interval of 75-79 years old. Elderly females were predominant as many as 20 people (67\%). Corneal abrasion was found in 4 subjects (13\%) with trichiasis due to entropion. The chi-square test of the correlation between trichiasis due to entropion and corneal abrasion obtain a p-value of 0.030 $(\mathrm{p}<0.05)$. In conclusion, there was a significant relationship between trichiasis due to entropion and the incidence of corneal abrasion.
\end{abstract}

Keywords: corneal abrasion, trichiasis, entropion

\begin{abstract}
Abstrak: Trikiasis merupakan pertumbuhan abnormal dari bulu mata yang mengakibatkan penggesekan bulu mata pada kornea yang dapat mengakibatkan terjadinya ulserasi maupun abrasi kornea. Salah satu penyebab trikiasis ialah entropion, yang dapat terjadi secara involusional (senilis) akibat proses penuaan. Penelitian ini bertujuan untuk mengetahui hubungan antara kejadian abrasi kornea dan trikiasis akibat entropion. Penelitian ini dilakukan pada orang lanjut usia di Panti Werdha Senja Cerah Paniki dan pasien yang berkunjung di UPTD Rumah Sakit Mata Provinsi Sulawesi Utara periode September-November 2019. Jenis penelitian ialah analitik prospektif. Hasil penelitian mendapatkan 30 orang lanjut usia dengan entropion involusional disertai trikiasis. Insidensi entropion involusional mencapai puncaknya pada interval 75-79 tahun (26,27\%) dan lebih banyak pada jenis kelamin perempuan (67\%).. Kejadian abrasi kornea pada pasien dengan trikiasis akibat entropion sebanyak 4 orang (13\%). Hasil uji chi-square terhadap hubungan antara trikiasis akibat entropion dan terjadinya abrasi kornea mendapatkan nilai signifikansi sebesar $0,030(\mathrm{p}<0,05)$. Simpulan penelitian ini ialah terdapat hubungan bermakna antara trikiasis akibat entropion dan terjadinya abrasi kornea.
\end{abstract}

Kata kunci: abrasi kornea, trikiasis, entropion

Trikiasis merupakan suatu kondisi pertumbuhan abnormal dari bulu mata yang mengakibatkan penggesekan bulu mata pada kornea. Penyebab paling sering dari kondisi ini antara lain: entropion, epi- blefaron, atau hanya pertumbuhan yang salah arah. Keadaan ini menyebabkan terjadinya iritasi pada kornea, dan jika dibiarkan dalam waktu lama maka ulserasi maupun abrasi pada kornea dapat terjadi. ${ }^{1}$ 
Trikiasis diklasifikasikan menurut jumlah bulu mata yang bertumbuh secara abnormal: trikiasis minor mengenai $<5$ silia dan trikiasis mayor mengenai $\geq 5$ silia.

Salah satu penyebab trikiasis, entropion, yaitu pelipatan palpebra ke arah dalam yang dapat terjadi secara involusional (senilis) akibat proses penuaan oleh karena adanya kelemahan otot-otot retraktor palpebra inferior dan migrasi otot orbikularis praseptal ke atas, maka palpebra inferior merupakan bagian yang sering terkena. ${ }^{1}$ Sedangkan, epiblefaron adalah suatu kondisi dimana terdapat lipatan horizontal ekstra pada bagian inferior mata yang mengarahkan bulu mata ke arah permukaan okular. $^{2}$

Entropion dapat ditemukan pada berbagai kelompok usia maupun jenis kelamin, namun lebih sering terjadi pada perempuan. Hal ini mungkin disebabkan oleh karakteristik anatomi, yaitu lempeng tarsal pada perempuan lebih kecil dari pada laki-laki. Entropion dapat mengenai salah satu mata (unilateral) maupun kedua mata (bilateral).,

Jumlah pasti frekuensi dari trikiasis belum diketahui. Trikiasis sederhana (trikiasis minor) yang mengenai hanya beberapa bulu mata ( $<5$ silia) biasanya lebih sering terjadi. Trikiasis difus (trikiasis mayor) yang mengenai seluruh tepi palpebra ( $\geq 5$ silia) lebih jarang terjadi, dan biasanya hanya terdapat pada negaranegara endemik trakoma. Morbiditas primer yang berhubungan dengan kejadian trikiasis ialah abrasi kornea dan keratitis mikroba. Kondisi ini dapat mengganggu fungsi penglihatan. Tidak diketahui berapa predileksi angka kejadian trikiasis bedasarkan jenis kelamin, namun jika ditinjau dari salah satu etiologinya yaitu entropion, maka angka kejadian trikiasis akan lebih tinggi pada perempuan. Trikiasis dapat terjadi pada semua usia namun lebih sering pada usia dewasa. ${ }^{5}$

Abrasi kornea merupakan cedera mata yang paling umum dan menjadi salah satu gangguan pada mata yang paling diabaikan. Kondisi ini dapat terjadi akibat adanya gangguan pada integritas epitel kornea maupun karena terkikisnya permukaan kornea sebagai akibat dari tekanan fisik eksternal. Abrasi epitel kornea dapat kecil atau besar, tergantung pada seberapa besar tekanan yang memengaruhi permukaan kornea. Abrasi kornea traumatik ialah jenis abrasi kornea klasik dimana trauma mekanik pada mata akan menghasilkan defek pada permukaan epitel kornea. ${ }^{6}$

Abrasi kornea merupakan gangguan mata paling sering terjadi terutama pada orang yang sering menggunakan lensa kontak. Insidensi trauma tidak tembus mata, yang termasuk abrasi kornea, adalah $1,57 \%$ per tahun secara internasional. Abrasi kornea merupakan kondisi yang umum terjadi, terhitung 12\%-13\% kasus baru pada 2 (dua) unit gawat darurat mata yang berbeda di Inggris. Dari semua kasus kondisi medis di Inggris, 6\% merupakan kasus mata. Trauma menyumbang $66 \%$ dari kasus-kasus ini, atau $4 \%$ dari keseluruhan kasus kondisi medis, dan abrasi kornea menyumbang $80 \%$ dari kasus trauma mata (3\% dari keseluruhan kasus). Insidensi abrasi kornea lebih tinggi pada orang-orang di usia produktif.,

Berdsarkan latar belakang ini maka penulis tertarik untuk mengetahui hubungan kejadian abrasi kornea pada pasien lanjut usia (lansia) dengan trikiasis akibat entropion

\section{METODE PENELITIAN}

Penelitian yang dilakukan menggunakan metode analitik prospektif dengan tujuan untuk mengetahui hubungan kejadian abrasi kornea pada pasien dengan trikiasis akibat entropion. Penelitian ini dilaksanakan di UPTD Rumah Sakit Mata Provinsi Sulawesi Utara dan Panti Werdha Senja Cerah Paniki pada bulan SeptemberNovember 2019 dengan meneliti semua orang lansia dengan diagnosis entropion yang sudah menunjukkan adanya trikiasis.

Kriteria inklusi penelitian merupakan orang lansia $>45$ tahun dengan entro-pion yang disertai trikiasis yang belum atau telah menunjukkan kondisi abrasi pada kornea. Kriteria eksklusi merupakan orang lansia tanpa entropion, adanya gangguan 
mental, dan yang tidak bersedia mengikuti kegiatan penelitian.

Pada pasien yang mengalami entropion involusional sehingga menyebabkan trikiasis selanjutnya dilakukan pemeriksaan pada permukaan kornea untuk menilai apakah terjadi abrasi kornea. Data penelitian diolah di SPSS v.25 dengan uji chi-square.

\section{HASIL PENELITIAN}

Data yang diambil untuk penelitian meliputi beberapa variabel, yaitu jenis kelamin, usia, pasien yang mengalami entropion dan trikiasis, serta mengalami abrasi kornea atau tidak. Pada periode penelitian didapatkan 30 orang lansia yang memenuhi kriteria inklusi penelitian, yaitu orang lansia dengan entropion involusional disertai trikiasis. Terdapat 1 orang lansia yang masuk kriteria eksklusi penelitian karena data yang tidak lengkap. Dari ke-30 orang lansia, didapatkan 10 orang dengan jenis kelamin laki-laki (33\%), dan 20 orang (67\%) dengan jenis kelamin perempuan.

Tabel 1 memperlihatkan pembagian usia berdasarkan World Health Organization (WHO). Distribusi pasien trikiasis akibat entropion terbanyak pada rentang usia 75-79 tahun, yaitu 8 orang $(26,67 \%)$. Seiring bertambahnya usia, terdapat peningkatan insidensi entropion involusional dan mencapai puncak pada interval 75-79 tahun, namun menurun lagi pada usia 80 tahun ke atas. Pada rentang usia 45-49 tahun dan 60-64 tahun tidak ditemukan lansia dengan entropion involusional.

Tabel 1. Distribusi berdasarkan pembagian lanjut usia menurut WHO

\begin{tabular}{ccc}
\hline $\begin{array}{c}\text { Usia } \\
\text { (tahun) }\end{array}$ & $\begin{array}{c}\text { f } \\
\text { (orang) }\end{array}$ & $\begin{array}{c}\text { Persentase } \\
(\boldsymbol{\%})\end{array}$ \\
\hline $45-49$ & 0 & 0 \\
$50-54$ & 2 & 6,67 \\
$55-59$ & 3 & 10 \\
$60-64$ & 0 & 0 \\
$65-69$ & 4 & 13,33 \\
$70-74$ & 6 & 20 \\
$75-79$ & 8 & 26,67 \\
$80-84$ & 4 & 13,33 \\
$85-89$ & 3 & 10 \\
Total & 30 & 100 \\
\hline
\end{tabular}

Kejadian abrasi kornea pada pasien dengan trikiasis akibat entropion didapatkan pada 4 dari 30 lansia (13\%) sedangkan yang lainnya 26 lansia (87\%) belum atau tidak mengalami abrasi kornea.

Tabel 2 memperlihatkan bahwa terdapat 2 dari 4 lansia yang mengalami abrasi kornea berusia di interval 50-54 tahun, kemudian 2 lainnya pada usia 65-69 tahun dan 80-84 tahun sedangkan 26 lansia lainnya yang tidak mengalami abrasi kornea berada pada interval usia yang beragam, mulai dari 45 tahun sampai 89 tahun.

Tabel 2. Tabulasi silang usia dan kejadian abrasi kornea

\begin{tabular}{cccc}
\hline \multirow{2}{*}{ Usia } & \multicolumn{2}{c}{ Abrasi Kornea } & Total \\
\cline { 2 - 3 } & Ya & Tidak & \\
\hline $45-49$ & $0(0 \%)$ & $0(0 \%)$ & $0(0 \%)$ \\
$50-54$ & $2(6,7 \%)$ & $0(0 \%)$ & $2(6,7 \%)$ \\
$55-59$ & $0(0 \%)$ & $3(10 \%)$ & $3(10 \%)$ \\
$60-64$ & $0(0 \%)$ & $0(0 \%)$ & $0(0 \%)$ \\
$65-69$ & $1(3,3 \%)$ & $3(10 \%)$ & $4(13,3 \%)$ \\
$70-74$ & $0(0 \%)$ & $6(20 \%)$ & $6(20 \%)$ \\
$75-79$ & $0(0 \%)$ & $8(26,7 \%)$ & $8(26,7 \%)$ \\
$80-84$ & $1(3,3 \%)$ & $3(10 \%)$ & $4(13,3 \%)$ \\
$85-89$ & $0(0 \%)$ & $3(10 \%)$ & $3(10 \%)$ \\
Total & $4(13,3 \%)$ & 26 & 30 \\
& & $(86,7 \%)$ & $(100 \%)$ \\
\hline
\end{tabular}

Tabel 3 memperlihatkan bahwa abrasi kornea terbanyak terdapat pada lansia dengan jenis kelamin laki-laki, yaitu 3 dari 10 lansia laki-laki mengalami abrasi kornea, serta 1 dari 20 lansia perempuan juga mengalami abrasi kornea.

Tabel 3. Tabulasi silang jenis kelamin dan kejadian abrasi kornea

\begin{tabular}{cccc}
\hline Jenis & \multicolumn{2}{c}{ Abrasi Kornea } & Total \\
\cline { 2 - 3 } kelamin & Ya & Tidak & \\
\hline Laki-laki & 3 & 7 & 10 \\
& $(10 \%)$ & $(23,33 \%)$ & $(33,3 \%)$ \\
Perempuan & 1 & 19 & 20 \\
& $(3,3 \%)$ & $(63,33 \%)$ & $(66,7 \%)$ \\
Total & 4 & 26 & 30 \\
& $(13,3 \%)$ & $(86,7 \%)$ & $(100 \%)$ \\
\hline
\end{tabular}

Pengujian hubungan dilakukan dengan 
aplikasi pengolahan statistik berupa SPSS menggunakan uji chi-square dengan tingkat signifikansi 5\% $(0,05)$. Hasil uji statistik hubungan antara trikiasis dan abrasi kornea mendapatkan nilai signifikansi $0,030(\mathrm{p}<0,05)$ yang menunjukkan bahwa trikiasis yang diakibatkan oleh entropion involusional memiliki hubungan bermakna dengan terjadinya abrasi kornea.

\section{BAHASAN}

Hasil penelitian ini memperlihatkan kejadian trikiasis akibat entropion berdasarkan usia (Tabel 1), yaitu terbanyak pada rentang usia 75-79 tahun sebanyak 8 orang $(26,67 \%)$. Angka kejadiannya kian menurun setelah melewati rentang usia 75-79 tahun dan tidak ditemukan lagi pada usia 89 tahun ke atas. Namun, mulai dari rentang usia 50-54 tahun angka kejadian kian naik, sampai mencapai puncaknya di 75-79 tahun. Hal ini dipengaruhi oleh proses penuaan, yaitu adanya kelemahan otot-otot retraktor palpebra inferior dan migrasi otot orbikularis praseptal ke bagian superior.

Angka kejadian trikiasis akibat entropion berdasarkan jenis kelamin (Tabel 3), mendapatkan bahwa angka kejadian terbanyak pada jenis kelamin perempuan, dengan perbandingan laki-laki : perempuan ialah 1 : 2 dari total 30 sampel. Pada jenis kelamin perempuan yaitu 20 orang $(67 \%)$, sedangkan pada jenis kelamin laki-laki berjumlah 10 orang (33\%). Hal ini disebabkan karena karasteristik anatomi yaitu lempeng tarsal pada perempuan lebih kecil dari pada lempeng tarsal pada laki-laki, sehingga memungkinkan kejadian trikiasis akibat entropion lebih sering terjadi pada perempuan. $^{3}$

Dari total 30 lanjut usia yang diteliti, kejadian abrasi kornea terdapat pada 4 orang (13\%), sedangkan 26 orang lainnya belum atau tidak mengalami abrasi kornea (Tabel 3).

Hasil analisis data bivariat yang mentabulasikan data antara usia dan kejadian abrasi kornea mendapatkan bahwa angka kejadian abrasi kornea terbanyak pada rentang usia 50-54 tahun dengan total
2 orang (6,7\%) (Tabel 2). Berdasarkan tabulasi silang jenis kelamin dan abrasi kornea, kejadian abrasi kornea paling banyak terdapat pada jenis kelamin laki-laki dengan total 3 dari 4 kasus atau 10\% dari total sampel (Tabel 3).

Hasil uji chi-square mendapatkan nilai signifikansi sebesar $0,030 \quad(\mathrm{p}<0,05)$ yang menunjukkan terdapat hubungan bermakna antara kedua variabel tersebut. Hal ini sesuai dengan yang dinyatakan oleh Verma $^{6}$ yaitu abrasi epitel kornea traumatik adalah jenis abrasi kornea klasik dimana trauma mekanik pada mata akan mengakibatkan defek pada permukaan epitel kornea; dalam hal ini yang menyebabkan trauma mekanik ialah penggesekan dari bulu mata oleh karena trikiasis.

\section{SIMPULAN}

Berdasarkan hasil penelitian ini dapat disimpulkan bahwa terdapat hubungan bermakna antara trikiasis akibat entropion dan terjadinya abrasi kornea. Lanjut usia yang terdiagnosis trikiasis akibat entropion didominasi oleh jenis kelamin perempuan sedangkan kejadian abrasi kornea didapatkan terbanyak pada jenis kelamin laki-laki.

Bagi dokter dan tenaga kesehatan disarankan agar melakukan skrining untuk menentukan apakah pasien yang terdiagnosis trikiasis mengalami abrasi kornea dan melakukan check up rutin pada orang lanjut usia untuk mengetahui apakah mereka sudah mengalami entropion involusional atau tidak. Selain itu, dokter perlu melakukan tindakan pencegahan kerusakan epitel kornea berupa melakukan tindakan epilasi atau pencabutan bulu mata yang tumbuh secara abnormal sesegera mungkin, sehingga meminimalkan risiko terjadinya abrasi kornea. Bagi masyarakat, perlu dilakukan edukasi tentang akibat kerusakan integritas epitel kornea dan dianjurkan untuk berperan secara aktif dalam hal pemeriksaan mata secara rutin karena abrasi kornea cenderung tidak memberikan gejala atau asimtomatik.

\section{DAFTAR PUSTAKA}

1. Sullivan JH, Shetlar DJ, Whitcher JP. 
Palpebra, Apparatus Lakrimalis, \& Air Mata. Oftalmologi Umum (17th ed). Jakarta: EGC, 2008; p. 80-1.

2. Kirkwood BJ, Kirkwood RA. Trichiasis: characteristics and management options. Insight. 2011;36(2):5-9.

3. Cantor LB, Rapuano CJ, Cioffi GA. Periocular malpositions and involutional changes. In: Basic Science and Clinical Course 2015-2016, Section 7, Orbit, Eyelids, and Lacrimal System. San Fransisco: American Academy of Ophthalmology, 2015; p. 236-42.

4. Yelena. Entropion involusional. Medicinus. 2015;4(7):19-26.
5. Rajak SN, O Collin JR, Burton MJ. Trachomatous trichiasis and its management in endemic countries. Surv Ophthalmol. 2012;57(2):105-35.

6. Verma A. Background: Corneal Abrasion. 2019 Jan 03. (Medscape). Available from: https://emedicine.medscape. com/article/1195402-overview

7. Knox KA, McIntee J. Nurse management of corneal abrasion. Br J. Nurs. 1995; 4(8):440-2, 459-60. (Medline).

8. Wong TY, Lincoln A, Tielsch JM, Baker SP. The epidemiology of ocular injury in Major US Automobile Corporation. Eye (Lond). 1998;12(Pt5):870-4. 